\title{
HeAlth VAlUES, PREFERENCE INCONSISTENCY, AND INSURANCE DEMAND
}

\author{
MATTHIAS WREDE
}

CESIFO WORKING PAPER NO. 1634

CATEGory 3: SOCIAL PROTECTION

DECEMBER 2005

\footnotetext{
An electronic version of the paper may be downloaded

- from the SSRN website:

wWw.SSRN.com

- from the CESifo website: www.CESifo-group.de
} 


\title{
HEALTh VALUES, PREFERENCE INCONSISTENCY, AND INSURANCE DEMAND
}

\begin{abstract}
Several empirical studies provide evidence that their actual health state affects people's attitudes towards health and medical care in hypothetical health states. In the tradition of behavioural economics this paper considers the actual health state as a point of reference and builds a model for studying the implications of this phenomenon on health insurance and on demand for medical care. It considers the insurance demand of different types of agents: naive individuals, individuals who are able to commit to medical care demand and sophisticated individuals. Furthermore, it raises the question of whether inconsistency of preferences reinforces or tones down moral hazard problems.
\end{abstract}

JEL Code: I11, G22, D82, D91.

Keywords: health insurance, medical care, health state, behavioural economics, prospect theory, time inconsistency.

\author{
Matthias Wrede \\ RWTH Aachen University \\ Department of Business and Economics \\ Templergraben 64 \\ 52056 Aachen \\ Germany \\ mwr@fiwi.rwth-aachen.de
}

First version: November 2005. 


\section{Introduction}

A large number of studies have tested empirically whether the actual health state affects the valuation of health in hypothetical future health states. The evidence is mixed: Some stated preference studies [see, e.g., Llewellyn-Thomas et al. (1993)] found that the respondent's health state does not influence the valuations, while other studies discovered a direct effect. Sackett and Torrance (1978) found that ratings for a life that would require dialysis were lower for the general public than they were for actual dialysis patients. Boyd et al. (1990) considered carcinoma of the rectum, and found out that utilities assigned to colostomy a common outcome of treatment for that disease - depend on the current health state. Kind and Dolan (1995) and Dolan (1996) found that persons in a state of poor health value such states relatively highly. They argue that people with past experience of illness know that they can adapt to poor health. Winter et al. (2003) asked a sample of elderly people living in congregate housing about their preferences for prolonging life. Frail persons expressed more preferences for a longer life under bad health conditions than the healthier participants did. King et al. (2004) interviewed veterans to measure their health values for different hypothetical health states involving a degenerative spine condition. King et al. (2004) came up with the result that health values for this disease, which were estimated by different techniques, were positively correlated with the currently perceived health state.

There are several explanations for the discrepancies between hypothetical and actual evaluations. First, stated preference studies are certainly affected by inadequate descriptions of health states. On the basis of a comparison of different explanations for discrepancies between hypothetical and actual evaluations, Jansen et al. (2000) argue that non-corresponding descriptions of hypothetical states explain most of the discrepancies. Second, the "new understanding" hypothesis refers to experience or knowledge. As Dolan (1999) points out, experience has at least three different dimensions: the period of illness, the time since the illness ended and the strength of the relationship between the ill person and the respondent. Since most studies capture only one or two dimensions of experience, the variety in the results is not surprising. Furthermore, Dolan (1999) stresses that knowledge of illness might also be influenced by anticipation of illness (the subjective probability of illness and the perceived time up to the outbreak of illness). Third, a change in the 
health state may create a real shift in valuation, i.e., a change in the preference ordering [Dolan (1996)]. Treadwell and Lenert (1999) survey additional empirical evidence which supports the hypothesis that the actual health state as a point of reference does affect valuations. To sum up, the evidence for a true valuation shift seems strong enough to start with the hypothesis that preferences on health ex-ante differ from preferences ex-post.

Many authors have stressed that a valuation shift has important implications for costbenefit and cost-effectiveness analysis [e.g., Dolan (1999) and Treadwell and Lenert (1999)]. If preferences of patients and non-patients differ, stated preference studies may be biased towards either group. More fundamentally, they raise the question of whose preferences should count at all. What are respondents' true preferences, when these change over time and across states? Without a convincing answer to this question, it seems almost impossible to use standard cost-benefit-analysis as a guideline for investment or for public policy. The same question has been raised in the literature on hyperbolic discounting or, more generally, on time-inconsistent preferences [put forward by Strotz (1956), Pollak (1968) and Laibson (1997)]. This literature envisions an agent with varying lifetime preferences as an aggregate over multiple selves. For normative purposes, it either applies the Pareto criterion [see, among others, Laibson (1997) and Diamond and Köszegi (2003)] which is, unfortunately, not a very discriminating instrument (since preferences of different selves are highly contradictory), or it aggregates selves with a welfare function, which lacks a convincing set of weights [see, for a discussion of this issue, Bernheim and Rangel (2005)].

Changing preferences for medical treatment should have an effect not only on attitudes but also on behavior. Recently, behavioral economics has started to develop models for the analysis of behavior in the area of social security and health economics when preferences are inconsistent. For example, Diamond and Köszegi (2003) consider the impact of quasihyperbolic discounting on retirement. Kopczuk and Slemrod (2005) show that the denial of death, i.e., of signals of mortality, leads to inconsistent behavior. Similarly, Köszegi (2003) analyzes patients' behavior when anxiety about the future leads them to avoid visits to their doctor, particularly if they feel really sick. Gruber and Köszegi (2002) discussed whether tax policy should play a role in the fight against addiction. Frank (2004) argues that behavioral economics has the potential to contribute substantially to health economics. Although he focuses on doctor-patient interactions and quality of care, 
he also briefly discusses health insurance and demand for health care. Richman (2005) stresses that psychology and behavioral economics provide a useful source for the analysis of Medicaid's development. This paper, too, applies the behavioral economic approach to a particular issue in health economics.

The aim of this paper is to analyze the implications of the change in preferences for economic behavior. The actual health state is considered as a point of reference for individual valuation. It was the prospect theory, introduced by Kahneman and Tversky (1979), which put forward the idea that the value of outcome is relative rather than absolute. Among others, Treadwell and Lenert (1999) and Winter et al. (2003) have already argued that prospect theory does indeed predict that the current health state should affect attitudes towards medical care in hypothetical states. ${ }^{1}$ Using this idea, this paper analyzes health insurance demand and demand for medical care. When people make an insurance contract, they make provisions for hypothetical health states. The main question is that of whether and how actual health state dependency affects health insurance markets and the demand for medical care. In order to predict how a valuation shift affects behavior, a decision-making model is required. This paper employs the approach used in the literature on hyperbolic discounting, which decomposes each agent into a sequence of multiple selves. The analysis does not directly apply the value function concept of prospect theory, but rather rests on expected utility theory. Furthermore, the paper also analyzes different degrees of rationality, namely the rationality of naive agents, who do not recognize the change in preferences, and of sophisticated agents, who do foresee the valuation shift, but nevertheless do not like the change in preferences. As moral hazard is a central issue in health insurance, the paper also analyzes the relationship between inconsistent preferences and moral hazard.

The main (positive) findings of the paper are: First, provided that healthier people underestimate the marginal willingness to pay for medical treatment, preference inconsistency reduces health insurance demand. This holds true, whether agents are naive or sophisticated. Second, sophisticated agents not only buy less insurance but also may increase savings in order to shift resources to healthier states. Third, when preference in-

\footnotetext{
${ }^{1}$ Stratmann-Schoene and Klose (2001) oppose this interpretation of prospect theory. In their view, prospect theory requires that the hypothetical health state be the point of reference.
} 
consistency meets ex-post moral hazard, necessary coinsurance may bring total insurance demand to a standstill.

The paper is organized as follows. The next section develops the basic economic model and determines the properties of a welfare maximum. In this context, it proposes a particular form of the welfare function. Section three characterizes the market for health insurance and defines the equilibrium concept. As a starting point, section four describes the equilibrium when medical care is not at the discretion of patients. Then, sections five to seven analyze the full model for different types of insured agents, namely naive agents, agents who are able to commit to medical care demand, and sophisticated agents. In order to get clear-cut results, a slightly simpler version of the model, which neglects the time dimension, is used in section eight. Section nine raises the question of whether inconsistency reinforces or tones down moral hazard problems. Finally, section ten concludes.

\section{Health state-dependent utility and medical care}

Ex-ante identical individuals are considered who lives for two periods. While an agent enjoys good health in the first period, he or she might fall ill in the second period. There are $n$ potential health states $H_{i}, i=1, \ldots, n$, in the second period, where $H_{1}$ indicates healthiness. Since the agent is well in the first period, the first period health state $H_{0}$ is equal to $H_{1}$. Probabilities of health states in the second period $p_{i}$ are exogenous, with $\sum_{i=1}^{n} p_{i}=1$. Thus, it is assumed that healthy living in the first period has no impact on the transition to second period states. The individual is endowed with $Y$ units of a composite good. Resources are used for consumption $(C)$ or for medical care $(M)$. The subscript 0 indicates the first period, second-period consumption is identified by the indicator of the health state. When the agent is in good health, medical care is superfluous. Thus, $M_{0}=M_{1}=0$, since waste of resources is never optimal. The marginal rate of transformation between consumption and medical care is state-dependent, but otherwise constant (constant returns to scale in production). It is denoted by $q_{i}$ which is also considered to be the price of medical care. The basic arguments of the instantaneous utility function are consumption and medical care. But preferences also depend on the health state while demanding medical care $H_{i}$ and possibly on the health state at the time of con- 
sideration $H_{j}$ : $u\left(C_{i}, M_{i}, H_{i}, H_{j}\right)$. After the agent becomes ill, it is only the actual health state which affects preferences: $j=i$. Utility of the agent in the second period is therefore $u_{i}=u\left(C_{i}, M_{i}, H_{i}, H_{i}\right)$. However, in the first period, it might also be the current health state which determines preferences on consumption and medical care in some or all states in the second period: $j=0$. Then, utility is $\tilde{u}_{i}=u\left(C_{i}, M_{i}, H_{i}, H_{0}\right)$. In general, the impact of the health state in the first period on the evaluation of health in the second period is state-dependent. A pure discounting effect, namely $\tilde{u}_{i}=\psi\left(H_{0}\right) u\left(C_{i}, M_{i}, H_{i}, H_{i}\right)$, where $\psi$ denotes some arbitrary function, is only a very special case which is not the focus of this analysis. Both, consumption and medical care are assumed to be normal goods. Without loss of generality, health states are ordered such that $m$ divides the set of states into two subsets. For all states with $i \leq m$, the first-period self evaluates medical care on the basis of the future health state; for all other states, the judgment depends on the health state at the date of consideration. Preferences are consistent if $m$ is equal to $n$, whereas they are otherwise inconsistent. The utility function is strictly concave and increases in $C$ and $M$ for each health state. Finally, a small open economy is considered. Hence, saving does not change the rate of interest $r$. Furthermore, the discount factor $\delta$ is equal to $1 /(1+r)$. Expected lifetime utility is

$$
U_{0}=u\left(C_{0}, 0, H_{0}, H_{0}\right)+\sum_{i=1}^{m} \delta p_{i} u\left(C_{i}, M_{i}, H_{i}, H_{i}\right)+\sum_{i=m+1}^{n} \delta p_{i} u\left(C_{i}, M_{i}, H_{i}, H_{0}\right) .
$$

Assuming that there is a large number of identical agents, the resource constraint per capita is

$$
C_{0}+\sum_{i=1}^{n} p_{i}\left(C_{i}+q_{i} M_{i}\right) \frac{1}{1+r}=Y .
$$

With consistent preferences, the optimum could easily be calculated by maximizing (1) subject to (2). As pointed out in the introduction, what the optimum actually is, is less clear with inconsistent preferences. In the case of unstable preferences, the agent can be considered as being composed of multiple agents (selves). A Pareto optimum is, then, a sequence of consumption and medical care such that it is impossible to make one self better off without harming at least one other self. One way of defining selves is to separate the individual into the first-period self with utility $U_{0}$ and the second-period selves with utilities $u_{i}$. Thus, a sequence of different selves can be considered. Then, a Pareto optimum 
maximizes $\alpha_{0} U_{0}+\sum_{i=1}^{n} \alpha_{i} u^{i}$ subject to the resource constraint for all feasible $\alpha$. But this program has the undesirable feature of the consumption of later selves counting twice. Furthermore, with consistent preferences, this program would not lead to the individual optimum (if $\alpha_{i} \neq 0$ ). An alternative would be to consider a simultaneous coexistence of different selves. While some selves evaluate health (at least in some states) on the basis of the first-period health state, the evaluation of other selves always depends on the actual health state. The former might be called the "inconsistent" type, since preferences depend on an arbitrary point of reference. In these circumstances, a Pareto optimum solves for all $\alpha$

$$
\begin{array}{rl}
\max _{C_{0}, C_{i}, M_{i}} & u\left(C_{0}, 0, H_{0}, H_{0}\right)+\sum_{i=1}^{m} \delta p_{i} u\left(C_{i}, M_{i}, H_{i}, H_{i}\right) \\
& +\sum_{i=m+1}^{n} \alpha \delta p_{i} u\left(C_{i}, M_{i}, H_{i}, H_{0}\right)+\sum_{i=m+1}^{n}(1-\alpha) \delta p_{i} u\left(C_{i}, M_{i}, H_{i}, H_{i}\right)
\end{array}
$$

s.t. $(2)$.

$\alpha$ is the weight of the inconsistent type, and $1-\alpha$ that of the consistent type. Rearranging the first-order conditions of this program for an interior solution yields: ${ }^{2}$

$$
\begin{aligned}
u_{C}^{0} & =u_{C}^{i}, \quad i=1, \ldots, m, \\
q_{i} & =\frac{u_{M}^{i}}{u_{C}^{i}}, \quad i=2, \ldots, m, \\
u_{C}^{0} & =\alpha \tilde{u}_{C}^{i}+(1-\alpha) u_{C}^{i}, \quad i=m+1, \ldots, n, \\
q_{i} & =\beta \frac{\tilde{u}_{M}^{i}}{\tilde{u}_{C}^{i}}+(1-\beta) \frac{u_{M}^{i}}{u_{C}^{i}}, \text { where } \beta=\frac{\alpha \tilde{u}_{C}^{i}}{\alpha \tilde{u}_{C}^{i}+(1-\alpha) u_{C}^{i}}, \quad i=m+1, \ldots, n .
\end{aligned}
$$

As far as preferences are consistent, the marginal utility of income should be equalized across states [see Breyer and Zweifel (1997)] and over time. Moreover, the marginal rate of substitution between medical care and the composite good should be equal to the marginal rate of transformation. In the range where preferences are inconsistent, marginal utility of income in the first period should be equal to a weighted average of type-specific marginal utilities of income. Similarly, the marginal rate of transformation should be equalized with a weighted average of marginal rates of substitution. When inconsistent types do

\footnotetext{
${ }^{2}$ The superscript indicates the state and the subscript the variable of partial differentiation.
} 
not count (i.e., when $\alpha=\beta=0$ ), a Pareto optimum is the individual optimum of a consistent decision maker. In the reverse case, where consistent types do not matter (i.e., when $\alpha=\beta=1$ ), a Pareto optimum coincides with the optimum of the inconsistent type. However, from a constitutional point of view, these extreme weights are hard to justify. Behind a veil of ignorance, the first-period type is as likely as the second-period type (since the representative agent lives with certainty for two periods). In other words, a constitutional welfare function should probably weigh both types equally: $\alpha=0.5$.

\section{Health insurance market and equilibrium}

In period one, the agent can divide his endowment $Y$ into consumption $C_{0}$, savings $S$ and health insurance, where the insurance premium is denoted by $P: Y=C_{0}+S+P$. In period two, the income consists of capital income $S(1+r)$ and an indemnity payment $I_{i}$, which depends on the current health state. Although the indemnity policy is less prominent than in former times, it is a good starting point for the analysis. Later on, a coinsurance tariff will also be considered. With his or her income $Y_{i}$, the agent finances consumption $C_{i}$ and medical care $q_{i} M_{i}$ :

$$
C_{i}=Y_{i}-q_{i} M_{i}, \quad \text { where } Y_{i}=S(1+r)+I_{i}, \quad i=1, \ldots, n \text {. }
$$

The insurance premium depends on the indemnity payment, on the price of health insurance and on a lump-sum element: $P=\sum_{i=2}^{n} \sigma_{i} I_{i}+F$, where $\sigma_{i}>0$ and $F \geq 0$. It is assumed that there is perfect price competition at the health insurance market. Furthermore, since the population is assumed to be homogeneous and preventive activities are assumed away, adverse selection and moral hazard do not occur. The timing of events is as follows: First, insurers determine health state-dependent prices $\sigma_{i}$. Second, individuals choose the indemnity payment for each state $I_{i}$. Finally, non-demanded contracts are withdrawn. A set of contracts is an equilibrium at the health insurance market (a) if no insured person would benefit from a withdrawal or a contract change, (b) if no individual without insurance would profit from insurance protection, (c) if the expected profit of each insurer is non-negative and (d) if no insurer could increase expected profits by changing a contract. At the equilibrium, due to perfect price competition, expected profits are zero. 
Then, the price of insurance equals the discounted probability, $\sigma_{i}=p_{i} /(1+r)$, and the lump-sum element matches per capita costs. Hence, first-period consumption is

$$
C_{0}=Y-S-\sum_{i=2}^{n} \frac{p_{i}}{1+r} I_{i}-F
$$

provided that insurance demand is not zero. Otherwise $C_{0}=Y-S$.

\section{Fixed medical expenditure}

As a starting point, health state-dependent but fixed medical expenditure is considered. Medical care is not a matter of choice: $M_{i}=\bar{M}_{i}$. This is a standard assumption in simple insurance market models [see Breyer and Zweifel (1997)]. Hence, in the second period the agent has nothing to decide. Furthermore, the utility function can be either reduced to $u_{i}=u_{i}\left(C_{i}\right)$ or to $\tilde{u}_{i}=\tilde{u}_{i}\left(C_{i}\right)$, where the latter is the inconsistent type. All functions are assumed to be concave. The agent solves

$$
\max _{S, I_{i}} u_{0}\left(C_{0}\right)+\sum_{i=1}^{m} \delta p_{i} u_{i}\left(C_{i}\right)+\sum_{i=m+1}^{n} \delta p_{i} \tilde{u}_{i}\left(C_{i}\right) \quad \text { s.t. (6) and (5). }
$$

From first-order conditions it follows that

$$
u_{C}^{0}=u_{C}^{i}, \quad i=1, \ldots, m, \quad \text { and } \quad u_{C}^{0}=\tilde{u}_{C}^{i}, \quad i=m+1, \ldots, n .
$$

Perceived marginal utility of income is equalized across states and over time. Due to the concavity of the utility functions, agents buy only partial insurance if, for each amount of income, the (perceived) marginal utility of income is smaller when the agent is sick than when he or she is well. In contrast, agents demand extra money in the case of illness if the marginal utility of income is lowest when agents are in good health. ${ }^{3}$ However, because of preference instability, the market equilibrium is non-optimal from a welfare point of view, provided that second-period selves are not completely neglected (i.e., $\alpha<1$ ). Society would prefer to give different amounts of resources to later selves depending on their health states. If, for all $i=m+1, \ldots, n$ and for all $x>0 \tilde{u}_{C}^{i}(x)<u_{C}^{i}(x)$, at the equilibrium $u_{C}^{0}<u_{C}^{i}$ would hold. Society would like to shift resources to the sick selves with preferences that

\footnotetext{
${ }^{3}$ See Cook and Graham (1977) and Breyer and Zweifel (1997) for an analysis with consistent preferences.
} 
differ from those of their ancestor at the expense of the first-period self, of the healthy second-period self and of the sick second-period self with the same preferences as those of their ancestor. This happens if the agent does not foresee that he or she needs specific consumption goods for an illness which are not included in the actual medical care (special diet, assistance for the disabled, etc.). If, on the contrary, for all $i=m+1, \ldots, n$ and for all $x>0 \tilde{u}_{C}^{i}(x)>u_{C}^{i}(x)$, healthy persons do not get enough of these. This would be the case if people could not imagine that sick persons had less opportunity to spend money on consumption goods.

\section{$5 \quad$ Naive agents}

While in the previous section the second-period self was completely passive, the focus now shifts to active selves. Medical care demand is no longer exogenous. At least three different cases with inconsistency can be distinguished between: First, the agent decides at the start on savings, insurance and state-dependent medical care (commitment). Second, the second-period self decides on medical care and the first-period self assumes that preferences do not change (naive agent). Third, the first-period agent foresees that the second-period agent not only has different preferences on medical care, but will also enforce them (sophisticated agent). This section considers the naive agent. He or she predicts that the later self will choose medical care $M_{i}$ so as to maximize either $u=u\left(C_{i}, M_{i}, H_{i}, H_{i}\right)$ or $\tilde{u}=u\left(C_{i}, M_{i}, H_{i}, H_{0}\right)$, depending on whether $i$ is smaller than $m+1$ or not. Perceived first-order conditions can be written as

$$
q_{i}=\frac{u_{M}^{i}}{u_{C}^{i}}, \quad i=2, \ldots, m, \quad \text { and } \quad q_{i}=\frac{\tilde{u}_{M}^{i}}{\tilde{u}_{C}^{i}} \quad i=m+1, \ldots, n .
$$

Then, the first-period agent faces the optimization problem

$$
\begin{array}{rl}
\max _{S, I_{i}} & u\left(C_{0}, 0, H_{0}, H_{0}\right)+\sum_{i=1}^{m} \delta p_{i} u\left(C_{i}, \tilde{M}_{i}, H_{i}, H_{i}\right)+\sum_{i=m+1}^{n} \delta p_{i} u\left(C_{i}, \tilde{M}_{i}, H_{i}, H_{0}\right) \\
\text { s.t. } & (6),(5) \text { and } \tilde{M}_{i}=\tilde{M}_{i}\left(S, I_{i}\right),
\end{array}
$$

where perceived medical care $\tilde{M}_{i}=\tilde{M}_{i}\left(S, I_{i}\right)$ is for $i=2, \ldots, n$ determined by (9). Firstorder conditions can be rearranged to

$$
u_{C}^{0}=u_{C}^{i}, \quad i=1, \ldots, m, \quad \text { and } \quad u_{C}^{0}=\tilde{u}_{C}^{i} \quad i=m+1, \ldots, n .
$$


The solutions $S$ and $I_{i}$ are the basis for the true decisions of later selves, who maximize $u\left(C_{i}, M_{i}, H_{i}, H_{i}\right)$ by choosing medical care such that

$$
q_{i}=\frac{u_{M}^{i}}{u_{C}^{i}}, \quad i=2, \ldots, n
$$

Perceived and true medical care demand coincide in states 1 to $m$, but differ otherwise. In general, ex-post marginal utility of income is not equalized across states where firstperiod agents are wrong about their second period preferences (since $u_{C}^{0}=\tilde{u}_{C}^{i}$ holds only for perceived not for true medical care demand). The result is not a welfare maximum (according to the definition given by (3)). $q_{i}=u_{M}^{i} / u_{C}^{i}$ would require $\alpha=0$, but for $\alpha=0$ $u_{C}^{0}=u_{C}^{i}$ has to hold. The outcome is suboptimal and typically deviates from the optimum in the direction described in the previous section:

Proposition 1 With inconsistent preferences and naive agents, the market equilibrium is not a Pareto optimum.

\section{Commitment}

When commitment technology exists, the first-period agent also determine medical care demand in all states of the second period. Commitment is possible if medical care is only provided for insured people and that insurance contracts specify the level of medical care for every possible disease. Because of the high demands on insurance contracts, on real insurance markets, commitment is, at most, imperfect. However, it is nevertheless worth analyzing commitment as a benchmark case. The optimization problem of the first-period self reads

$$
\begin{array}{cl}
\max _{S, I_{i}, M_{i}} & u\left(C_{0}, 0, H_{0}, H_{0}\right)+\sum_{i=1}^{m} \delta p_{i} u\left(C_{i}, M_{i}, H_{i}, H_{i}\right)+\sum_{i=m+1}^{n} \delta p_{i} u\left(C_{i}, M_{i}, H_{i}, H_{0}\right) \\
& \text { s.t. (6) and (5). }
\end{array}
$$

First-order conditions are given by (11) and (9). The first-period self behaves as if he or she were naive. With commitment technology, the indemnity payment in all states and savings is as high as if the agent were naive. Therefore, with an exogenous price of medical 


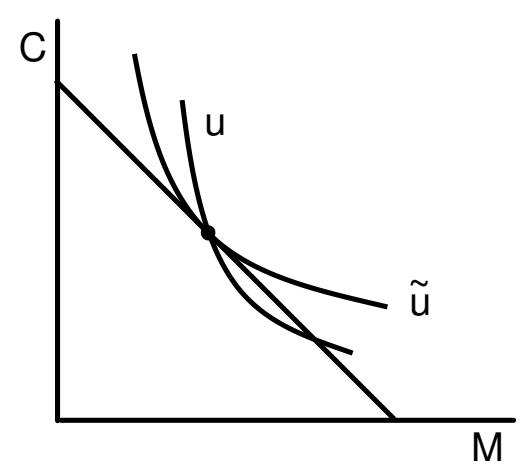

Figure 1: Naive behavior vs. commitment: HWTP

care, the budget constraint in each state in period two is, with commitment, the same as it is with naiveness. Whether or not medical care demand is higher with commitment than it is with naiveness depends on the direction of the valuation shift. It is assumed that indifference curves are either flatter or steeper everywhere after the shift:

Assumption 1 (HWTP) In health state $i$, with $i \geq m+1$, the real marginal willingness to pay for medical care is, for all consumption-medical care bundles, higher than the hypothetical marginal willingness to pay, i.e., $u_{M}^{i} / u_{C}^{i}>\tilde{u}_{M}^{i} / \tilde{u}_{C}^{i}$.

Assumption 2 (LWTP) In health state $i$, with $i \geq m+1$, the real marginal willingness to pay for medical care is, for all consumption-medical care bundles, lower than the hypothetical marginal willingness to pay, i.e., $u_{M}^{i} / u_{C}^{i}<\tilde{u}_{M}^{i} / \tilde{u}_{C}^{i}$.

The former assumption is justified, e.g., by the findings of Winter et al. (2003). In each state where assumption 1 holds, medical care demand with commitment technology is lower than with naiveness [see figure 1]. The opposite holds true under assumption 2.

To summarize:

Proposition 2 Naive agents save and buy insurance to the same degree as agents with commitment technology do. Medical care demand is higher (lower) with naiveness than with commitment, provided that assumption 1 (2) holds. 


\section{Sophisticated agents}

A sophisticated agent takes the real behavior of later selves into account. Even a sophisticated agent has inconsistent preferences, but he or she is aware of the inconsistency. Under assumption 1, the first period self possibly wants to value bad health states lower than good health states. A sophisticated agent solves

$$
\max _{S, I_{i}} u\left(C_{0}, 0, H_{0}, H_{0}\right)+\sum_{i=1}^{m} \delta p_{i} u\left(C_{i}, M_{i}, H_{i}, H_{i}\right)+\sum_{i=m+1}^{n} \delta p_{i} u\left(C_{i}, M_{i}, H_{i}, H_{0}\right)
$$

s.t. (6), (5) and $M_{i}=M_{i}\left(S, I_{i}\right)$,

where each first-order condition in the second period $q_{i}=u_{M}^{i} / u_{C}^{i}$, for $i=2, \ldots, n$ defines a function $M_{i}\left(S, I_{i}\right)$. Since $C_{i}=S(1+r)+I_{i}-q_{i} M_{i}$,

$$
\frac{\partial M_{i}}{\partial S}=(1+r) \frac{\partial M_{i}}{\partial I_{i}}>0
$$

where the inequality follows from the normal-good assumption. Using these properties, first-order conditions can be rearranged to

$$
u_{C}^{0}=u_{C}^{i}, \quad i=1, \ldots, m, \quad \text { and } \quad u_{C}^{0}=\tilde{u}_{C}^{i}+\left(\tilde{u}_{M}^{i}-q_{i} \tilde{u}_{C}^{i}\right) \frac{\partial M_{i}}{\partial I_{i}} \quad i=m+1, \ldots, n .
$$

If assumption 1 holds, marginal utility of income is higher in the second period than in the first period: $u_{C}^{0}<\tilde{u}_{C}^{i}$. It is also higher than in those states where there is no difference between the preferences of the succeeding selves. If, from the point of view of the firstperiod self, the decision on medical care in the second period is suboptimal, he or she devotes less resources to this particular state.

In order to form a precise idea of how the agents react to preference differences, it is useful to consider the two-state case, where the agent is either healthy or sick in the second period. Furthermore, the range of utility functions will be restricted to $u_{i}=v_{i}\left(C_{i}, \beta M_{i}\right)$ and $\tilde{u}_{i}=v_{i}\left(C_{i}, M_{i}\right)$. The actual health state affects utility only via the $\beta$. If $\beta$ were equal to one, the first-period self agrees with the second-period self on medical care. Otherwise, there is disagreement. The first-order conditions (16) for $m=1$ and $n=2$ define $S(\beta)$ 
and $I_{2}(\beta)$ with

$$
\begin{aligned}
\frac{d S}{d \beta}= & \left\{\left[\frac{M_{2} \tilde{u}_{C M}^{2}}{\beta}-q_{2} \tilde{u}_{C C}^{2}+\left(\frac{\tilde{u}_{M M}^{2} M_{2}}{\beta}-\left(1+\frac{M_{2}}{\beta}\right) q_{2} \tilde{u}_{C M}^{2}+q_{2}^{2} \tilde{u}_{C C}^{2}\right) \frac{\partial M_{2}}{\partial I_{2}}\right] \frac{\partial M_{2}}{\partial \beta}\right. \\
& \left.+\left(\tilde{u}_{M}^{2}-q_{2} \tilde{u}_{C}^{2}\right) \frac{\partial^{2} M_{2}}{\partial I_{2} \partial \beta}\right\} u_{C C}^{0} \frac{p_{2}}{(1+r)} \frac{1}{\Delta}, \\
\frac{d I_{2}}{d \beta}= & -\left[\frac{u_{C C}^{0}+(1+r) u_{C C}^{1}}{u_{C C}^{0} p_{2} /(1+r)}\right] \frac{d S}{d \beta},
\end{aligned}
$$

and thus

$$
\frac{d C_{0}}{d \beta}=\left[\frac{(1+r) u_{C C}^{1}}{u_{C C}^{0}}\right] \frac{d S}{d \beta} \text { and } \frac{d Y_{2}}{d \beta}=-(1+r)\left[\frac{\left(1-p_{2}\right) u_{C C}^{0}+(1+r) u_{C C}^{1}}{u_{C C}^{0} p_{2}}\right] \frac{d S}{d \beta},
$$

where

$$
\Delta=\left|\begin{array}{ll}
u_{C C}^{0}+(1+r) u_{C C}^{1} & u_{C C}^{0} \frac{p_{2}}{(1+r)} \\
b 1 & b 2
\end{array}\right|
$$

$b 1$ and $b 2$ are the partial derivatives of the second first-order condition with reference to $S$ and $I_{2}$, respectively. Due to second-order conditions, $\Delta$ is positive. Since $\operatorname{sign}(d S / d \beta)=$ - sign $\left(d I_{2} / d \beta\right)$, the agent adapts savings and insurance to changes in the preference parameter $\beta$ in opposite directions. Moreover, $C_{0}$ follows $S$, whereas second-period income $Y_{2}$ follows $I_{2}$. However, the sign of $d S / d \beta$ is ambiguous. An increase in $\beta$ tends to push savings and to depress insurance demand, particularly if it strengthens the income effect and if assumption 1 holds. In such a case, the first-period self is willing to use a decrease in the indemnity payment to push the behavior of the second-period self in the right direction. Moreover, the agent shifts income to the healthy state, where there is no difference in preferences. Since $\beta=1$ also characterizes the behavior of the naive agent, under these circumstances a sophisticated agent saves more and insures less than a naive agent does and, according to the results of the last section, also than an agent with commitment technology does.

The well-being of the second-period self depends on his or her income $Y_{i}$. Thus, the later self prefers a sophisticated ancestor to other types of agent if $Y_{i}$ is higher than otherwise. But even if income is lower, the later self may prefer a sophisticated ancestor to one with access to commitment technology because medical care is at his or her discretion. 
An example: The results can be demonstrated by a simple additive-separable square root utility function: $u=\sqrt{C_{i}}+\beta \sqrt{a M_{i}}-H_{i}$ and $\tilde{u}=\sqrt{C_{i}}+\sqrt{a M_{i}}-H_{i}$. The marginal willingness to pay for medical care of the second-period self exceeds that of the firstperiod self. Per capita costs of insurance $F$ are assumed away. Using the superscripts s (sophisticated behavior), c (commitment) and n (naive behavior), in the two-state case the behavior is given by:

$$
\begin{gathered}
S^{c}=S^{n}=\frac{q_{2} Y}{a p_{2}+q_{2}(2+r)}<\frac{q_{2} Y\left(a \beta^{2}+q_{2}\right)}{a^{2} \beta^{2} p_{2}+q_{2}^{2}(2+r)+a \beta q_{2}\left(2 p_{2}+\beta\left(2+r-p_{2}\right)\right)}=S^{s}, \\
C_{0}^{c}=C_{0}^{n}=(1+r) S^{c}<(1+r) S^{s}=C_{0}^{s}, \\
Y_{2}^{c}=Y_{2}^{n}=\left(1+\frac{a}{q_{2}}\right)(1+r) S^{c}>\frac{\left(a \beta+q_{2}\right)^{2}}{\left(a \beta^{2}+q_{2}\right) q_{2}}(1+r) S^{s}=Y_{2}^{s}, \\
C_{2}^{c}=C_{0}^{c}>\left(\frac{a \beta+q_{2}}{a \beta^{2}+q_{2}}\right)^{2} C_{0}^{s}=C_{2}^{s}<C_{0}^{s} .
\end{gathered}
$$

The sophisticated agent saves and consumes more in the first period than other types of agents do. Hence, consumption in the good state is also higher. The indemnity payment is smaller and, therefore, income is lower in the bad state. Finally, the successor of the sophisticated self consumes less in the bad state than in the good state.

Supposing there are two different types of insurance contracts on the market: basic insurance and supplementary insurance. If there are per capita costs for supplementary insurance and if it is only possible to take out a supplementary policy on top of a basic insurance contract, sophisticated agents can simply reduce the insurance coverage. They will probably not enter into a supplementary contract if the basic insurance policy is rather generous.

To sum up, the results are ambiguous:

Proposition 3 Sophisticated agents without commitment will only typically save more and buy less insurance than agents with commitment technology and than naive agents will (given assumption 1). 


\section{Partial insurance}

The basic result of the previous sections could be elaborated somewhat more clearly in a slightly simpler framework. First, the number of health states is reduced to two: $m=$ $1, n=2$. Second, savings are omitted: a one-period version of the model is used. Third, the instantaneous utility function is additive separable in $C$ and $M$. The valuation shift affects only the direct benefits of medical care. Fourth, per capita insurance costs are zero. The agent pays a premium $P=p I$ in both states, where $I$ is the indemnity payment. ${ }^{4}$ Thus, consumption is

$$
C_{1}=Y-p I \quad \text { and } \quad C_{2}=Y+(1-p) I-q M
$$

There are still two selves: one before uncertainty is resolved, and one afterwards. The sick later self chooses $M$, so as to maximize instantaneous utility $u=u\left(C_{2}, M, H_{2}, H_{2}\right)$. The first-order condition $u_{M}^{2}-q u_{C}^{2}=0$ determines medical care demand $M$. The earlier self solves

$$
\max _{I}(1-p) u\left(C_{1}, 0, H_{1}, H_{1}\right)+p u\left(C_{2}, M, H_{2}, H_{0}\right) \text { s.t. }(20) \text { and } M=M(I) .
$$

$M=M(I)$ stems from the perceived behavior of the sick later self. Due to the normal good assumption, $d M / d I>0$ holds, irrespective of the self's type. The first-order condition is

$$
p(1-p)\left(\tilde{u}_{C}^{2}-u_{C}^{1}\right)+p\left[\tilde{u}_{M}^{2}-q \tilde{u}_{C}^{2}\right] \frac{d M}{d I}=0,
$$

where $\tilde{u}=u\left(C_{2}, M, H_{2}, H_{0}\right)$. Were preferences consistent, the term in square brackets would be zero and the agent would equalize marginal utilities of income and (because of the additive-separable utility function) would choose $C_{1}=C_{2}$ and thus $I=q M$. The same holds true for inconsistent preferences if the agent is naive or has commitment technology at his or her disposal. However, a naive agent purchases full coverage for expected medical care demand, but not for real demand. Under assumption 1, insurance is only partial, whereas under assumption 2, overinsurance takes place. Furthermore, under assumption 1, a sophisticated agent chooses $C_{1}>C_{2}$ and thus $I<q M$ since the term in square brackets is negative. Under assumption 2 the inequality directions are reversed.

\footnotetext{
${ }^{4}$ In order to simplify notation, subscripts are omitted where possible.
} 
Proposition 4 Insurance is only partial, irrespective of whether the first-period agent is naive or sophisticated, provided that assumption 1 holds. Under assumption 2, the indemnity payment exceeds realized expenditure for medical care.

\section{Inconsistency meets moral hazard}

In order to discuss the interdependency of inconsistency and ex-post moral hazard, it is again useful to use the simple model of the previous section. An ex-post moral hazard problem arises when insurers subsidize medical expenditure instead of making lump sum payments, provided that the "necessity" of the agent's medical care demand is not verifiable (hidden information) and that the insurer cannot directly restrict medical care demand. ${ }^{5}$ The insured party pays in both states the premium $P=s p q \bar{M}$, where $s$ is the matching rate, with $0 \leq s \leq 1,{ }^{6}$ and $\bar{M}$ is the average medical care demand in the bad health state. $1-s$ is the coinsurance rate and there is neither a stop loss nor a maximum benefit. Consumption is then

$$
C_{1}=Y-s p q \bar{M} \quad \text { and } \quad C_{2}=Y-s p q \bar{M}-(1-s) q M
$$

The sick later self chooses $M$ so as to maximize instantaneous utility $u=u\left(C_{2}, M, H_{2}, H_{2}\right)$ taking average medical care demand as given. The first-order condition reads

$$
u_{M}^{2}-(1-s) q u_{C}^{2}=0,
$$

which defines $M(s)$, with $d M / d s>0$. Insurance distorts the demand for medical care. Ceteris paribus the agent demands too much medical care. The earlier self maximizes expected utility $E U=(1-p) u\left(C_{1}, 0, H_{1}, H_{1}\right)+p u\left(C_{2}, M, H_{2}, H_{0}\right)$, where $u\left(C_{2}, M, H_{2}, H_{0}\right)$ is again denoted by $\tilde{u}$. If, on the one hand, the agent were able to choose the subsidy rate, and, on the other hand, neglected the impact of medical care demand on the premium (i.e., took the average as given), he or she would choose the subsidy rate equal to one, whatever the degree of consistency might be. Given a zero price of medical care, each later self

\footnotetext{
${ }^{5}$ Ex-post-moral hazard was first analyzed by Zeckhauser (1970).

${ }^{6}$ The analysis is restricted to linear health insurance although a non-linear scheme is in general optimal [see Spence and Zeckhauser (1971) and Blomquist (1997)].
} 
increases $M$ infinitely, since that is the cheapest way to raise the utility level. However, since the insurer would go bankrupt, no market equilibrium with health insurance and behavior of this kind exists. A market equilibrium exists if insurers choose the subsidy rate and the premium themselves. In order to get their share of the market, they choose the matching rate and the premium as to maximize the insured person's expected utility taking the perceived and the real impact of subsidies on medical care demand into account. It is assumed that the insurer is able to estimate correctly the real medical care demand on which the calculation of the premium has to be based. Since competition forces insurers to set the premium as low as possible, i.e., $P=\operatorname{spq} \bar{M}$, the subsidy rate can be considered as a single control variable. The optimization problem is therefore

$$
\max _{s}(1-p) u\left(C_{1}, 0, H_{1}, H_{1}\right)+p u\left(C_{2}, \hat{M}, H_{2}, H_{0}\right) \text { s.t. }(23), \bar{M}=M(s) \text { and } \hat{M}=\hat{M}(s) \text {. }
$$

$\hat{M}=\hat{M}(s)$ is defined by (24) if the agent is sophisticated and by a corresponding firstorder condition if the agent is naive. First, $s$ has to be smaller than one, since agents would increase demand for medical care ad infinitum and the insurance company would go bankrupt if $s$ were equal to or greater than one. Second, the marginal impact on expected utility of a change in the subsidy rate is

$$
\begin{array}{r}
-p q \bar{M}\left(\left[(1-p) u_{C}^{1}+p \tilde{u}_{C}^{2}\right]+p q \hat{M} \tilde{u}_{C}^{2}\right. \\
-\left[s p q\left((1-p) u_{C}^{1}+p \tilde{u}_{C}^{2}\right)\right] \frac{d M}{d s}+p\left[\tilde{u}_{M}^{2}-(1-s) q \tilde{u}_{C}^{2}\right] \frac{d \hat{M}}{d s} .
\end{array}
$$

If preferences were consistent, the second term in square brackets in the second row would be zero, $\bar{M}=\hat{M}$ and $u=\tilde{u}$ would hold, and the optimum matching rate would be strictly positive [see Breyer and Zweifel (1997)]. If $s$ were zero, the second row would be zero, and the first row would be positive because of $C_{1}>C_{2}$. With inconsistent preferences, behavior changes, depending on the direction of the valuation shift. Under assumption 1 , the insurance market may break down, i.e., a zero subsidy rate may be optimal. For a naive agent and $s=0$, the second row is zero, but the first row may be zero or negative if $\bar{M}>\hat{M}$. For a sophisticated agent and $s=0$, the first row is clearly positive, but the second row is negative since the second term in square brackets is negative. For a naive agent, the direct marginal costs of a subsidy may be higher than the direct perceived 
marginal benefits, whereas a sophisticated agent takes into account that the demand for medical care is already without a subsidy beyond the preferred level.

Under assumption 2, the market works (although imperfectly). A zero-matching rate is certainly non-optimal, since the first row is positive and the second row is either zero or positive.

To sum up:

Proposition 5 With hidden information, inconsistency of preferences may lead to a collapse of the health insurance market if assumption 1 holds.

\section{Concluding remarks}

According to empirical studies, their actual health state affects people's attitudes of towards health and medical care in hypothetical health states. This paper has analyzed the implications of this phenomenon on health insurance and demand for medical care. It has built a two-period model of insurance demand where the actual health state in the first period is a point of reference for valuation of second-period needs. It has decomposed agents into two selves: The first-period self makes insurance contracts, the second-period self buys medical care. The analysis has come up with the following results: First, from a welfare point of view marginal utilities of income should not be equalized across health states and the marginal rate of transformation should differ from an individual marginal rate of substitution if preferences of both types of selves count. The paper argues that this should be the case. Second, if medical care demand is exogenous (but state-dependent) the interests of later selves are neglected. The market equilibrium is not a welfare maximum (if preferences of first-period and second-period selves count). This also holds true if medical care is endogenous. Third, naive agents save and buy insurance as much as agents with commitment technology do, but medical care demand is higher with naiveness if healthy people underestimate the marginal willingness to pay for medical care. Fourth, sophisticated agents without commitment technology will typically save more and buy less insurance than naive agents and agents with commitment technology will. Fifth, excluding

the opportunity to adapt savings, a sophisticated agent with inconsistent preferences, as 
well as a naive agent, chooses only partial insurance if healthy people underestimate the marginal willingness to pay for medical care. Sixth, with hidden information inconsistency of preferences may lead to a collapse of the health insurance market.

To put it in a nutshell, provided that healthy people underestimate the marginal willingness to pay for medical care, preference inconsistency leads to a reduction of health insurance demand. Under these circumstances, the paper makes some clear predictions which are open to empirical testing. First, one prediction is that health insurance coverage is smaller than expected from an ex-post point of view. In particular, the market for supplementary insurance would be too small. Second, the paper predicts that underinsurance is severest where the discrepancy between the people who decide on insurance demand and the actual patients is very large. Long-term care seems to be a good example of a large discrepancy. Inconsistency of preferences might be part of the explanation for the extremely small market size of long-term care insurance [see Congressional Budget Office (2004)] beside adverse selection, moral hazard, administrative costs and nondiversifiable intertemporal risk [see Norton (2000)].

Provided that healthy people underestimate the marginal willingness to pay for medical care and long-term care, the paper has also simple policy implications. On the one hand, preference inconsistency justifies obligatory basic health insurance and long-term care insurance. On the other hand, obligatory insurance should not cover all expenditure for medical care and long-term care that sick and old persons may ask for.

Finally, this paper's approach has, in particular, one shortcoming which restricts its domain. At least the welfare analysis requires that health states and probabilities be exogenous. Otherwise, the nature and "number" of selves would be endogenous which forbids conventional welfare analysis. However, for a positive analysis this approach could be applied to many other areas where valuations and behavior may depend in an inconsistent manner on state variables like age, cognitive ability, human capital stock, etc.

\section{References}

Bernheim BD and Rangel A (2005). Behavioral public economics: Welfare and policy analysis with non-standard decision makers. NBER Working Paper 11518. 
Blomquist $\AA$ (1997). Optimal non-linear health insurance. Journal of Health Economics 16: 303-321.

Boyd NF, Sutherland HJ, Heasman KZ, Tritchler DL, Cummings BJ (1990). Whose utilities for decision analysis? Medical Decision Making 10. 58-67.

Breyer F and Zweifel P (1997). Health economics. Oxford University Press. Oxford.

Congressional Budget Office (2004). Financing long-term care for the elderly.

Cook P und Graham D (1977). The demand for insurance protection: The case of irreplaceable commodities. Quarterly Journal of Economics 91. 143-156.

Diamond P and Köszegi B (2003). Quasi-hyperbolic discounting and retirement. Journal of Public Economics 87. 1839-1872.

Dolan P (1996). The effect of experience of illness on health state valuation. Journal of Clinical Epidemiology 49. 551-564.

Dolan P (1999). Whose preferences count? Medical Decision Making 19. 482-486.

Frank RG (2004). Behavioral economics and health economics. NBER Working Paper 10881.

Gruber B and Köszegi B (2002). A theory of government regulation of addictive bads: optimal tax levies and tax incidence for cigarette excise taxation. NBER Working Paper 8777.

Jansen SJ, Stiggelbout AM, Wakker PP, Nooij MA, Noordijk EM and Kievit J. (2000). Unstable preferences: A shift in valuation or an effect of the elicitation procedure? Medical Decision Making 20. 62-71.

Kahneman D and Tversky A (1979). Prospect theory: An analysis of decisions under risk. Econometrica 47. 276-287.

Kind P and Dolan P (1995). The effect of past and present illness experience on the valuations of health states. Medical Care 33. AS255-263. 
King JT, Tsevat J and Roberts MS (2004). Positive association between current health and health values for hypothetical disease states. Medical Decision Making 24. 367-378.

Kopczuk W and Slemrod J (2005). Denial of death and economic behavior. NBER Working Paper 11485.

Köszegi B (2003). Health anxiety and patient behavior. Journal of Health Economics 22.1073-1084.

Laibson D (1997). Golden eggs and hyperbolic discounting. Quarterly Journal of Economics 112. $443-477$.

Llewellyn-Thomas HA, Sutherland HJ and Thiel EC (1993). Do patients' evaluations of a future health state change when they actually enter that state? Medical Care 31. 1002-1012.

Norton EC (2000). Long-term care. In: A.J. Culyer and J.P. Newhouse. Handbook of Health Economics. Elsevier.

Pollak RA (1968). Consistent planning. Review of Economic Studies 35. 201208.

Richman BD (2005). Behavioral economics and health policy: Understanding Medicaid's failure. Duke Law Scholl Research Paper 62.

Sackett DL, Torrance GW (1978). The utility of different health states as perceived by the general public. Journal of Chronic Disease 31. 697-704.

Spence A and Zeckhauser R (1971). Insurance, information and individual action. American Economic Review, Papers and Proceedings 61. 380-387.

Stratmann-Schoene D and Klose T (2001). Health values and prospect theory: A comment. Medical Decision Making 21. 57-59.

Strotz RH (1956). Myopia and inconsistency in dynamic utility maximization. Review of Economic Studies 23. 165-180. 
Treadwell JR and Lenert LA (1999). Health values and prospect theory. Medical Decision Making 19. 344-352.

Winter L, Lawton MP and Ruckdeschel K (2003). Preferences for prolonging life: A prospect theory approach. International Journal of Aging and Human Development 56. $155-170$.

Zeckhauser R (1970). Medical insurance: A case study of the tradeoff between risk spreading and appropriate incentives. Journal of Economic Theory 2. 10-26. 


\section{CESifo Working Paper Series}

(for full list see www.cesifo-group.de)

1569 Jovan Žamac, Pension Design when Fertility Fluctuates: The Role of Capital Mobility and Education Financing, October 2005

1570 Piotr Wdowinski and Aneta Zglinska-Pietrzak, The Warsaw Stock Exchange Index WIG: Modelling and Forecasting, October 2005

1571 J. Ignacio Conde-Ruiz, Vincenzo Galasso and Paola Profeta, Early Retirement and Social Security: A Long Term Perspective, October 2005

1572 Johannes Binswanger, Risk Management of Pension Systems from the Perspective of Loss Aversion, October 2005

1573 Geir B. Asheim, Wolfgang Buchholz, John M. Hartwick, Tapan Mitra and Cees Withagen, Constant Savings Rates and Quasi-Arithmetic Population Growth under Exhaustible Resource Constraints, October 2005

1574 Christian Hagist, Norbert Klusen, Andreas Plate and Bernd Raffelhueschen, Social Health Insurance - the Major Driver of Unsustainable Fiscal Policy?, October 2005

1575 Roland Hodler and Kurt Schmidheiny, How Fiscal Decentralization Flattens Progressive Taxes, October 2005

1576 George W. Evans, Seppo Honkapohja and Noah Williams, Generalized Stochastic Gradient Learning, October 2005

1577 Torben M. Andersen, Social Security and Longevity, October 2005

1578 Kai A. Konrad and Stergios Skaperdas, The Market for Protection and the Origin of the State, October 2005

1579 Jan K. Brueckner and Stuart S. Rosenthal, Gentrification and Neighborhood Housing Cycles: Will America’s Future Downtowns be Rich?, October 2005

1580 Elke J. Jahn and Wolfgang Ochel, Contracting Out Temporary Help Services in Germany, November 2005

1581 Astri Muren and Sten Nyberg, Young Liberals and Old Conservatives - Inequality, Mobility and Redistribution, November 2005

1582 Volker Nitsch, State Visits and International Trade, November 2005

1583 Alessandra Casella, Thomas Palfrey and Raymond Riezman, Minorities and Storable Votes, November 2005

1584 Sascha O. Becker, Introducing Time-to-Educate in a Job Search Model, November 2005 
1585 Christos Kotsogiannis and Robert Schwager, On the Incentives to Experiment in Federations, November 2005

1586 Søren Bo Nielsen, Pascalis Raimondos-Møller and Guttorm Schjelderup, Centralized vs. De-centralized Multinationals and Taxes, November 2005

1587 Jan-Egbert Sturm and Barry Williams, What Determines Differences in Foreign Bank Efficiency? Australian Evidence, November 2005

1588 Steven Brakman and Charles van Marrewijk, Transfers, Non-Traded Goods, and Unemployment: An Analysis of the Keynes - Ohlin Debate, November 2005

1589 Kazuo Ogawa, Elmer Sterken and Ichiro Tokutsu, Bank Control and the Number of Bank Relations of Japanese Firms, November 2005

1590 Bruno Parigi and Loriana Pelizzon, Diversification and Ownership Concentration, November 2005

1591 Claude Crampes, Carole Haritchabalet and Bruno Jullien, Advertising, Competition and Entry in Media Industries, November 2005

1592 Johannes Becker and Clemens Fuest, Optimal Tax Policy when Firms are Internationally Mobile, November 2005

1593 Jim Malley, Apostolis Philippopoulos and Ulrich Woitek, Electoral Uncertainty, Fiscal Policy and Macroeconomic Fluctuations, November 2005

1594 Assar Lindbeck, Sustainable Social Spending, November 2005

1595 Hartmut Egger and Udo Kreickemeier, International Fragmentation: Boon or Bane for Domestic Employment?, November 2005

1596 Martin Werding, Survivor Benefits and the Gender Tax Gap in Public Pension Schemes: Observations from Germany, November 2005

1597 Petra Geraats, Transparency of Monetary Policy: Theory and Practice, November 2005

1598 Christian Dustman and Francesca Fabbri, Gender and Ethnicity - Married Immigrants in Britain, November 2005

1599 M. Hashem Pesaran and Martin Weale, Survey Expectations, November 2005

1600 Ansgar Belke, Frank Baumgaertner, Friedrich Schneider and Ralph Setzer, The Different Extent of Privatisation Proceeds in EU Countries: A Preliminary Explanation Using a Public Choice Approach, November 2005

1601 Jan K. Brueckner, Fiscal Federalism and Economic Growth, November 2005 
1602 Steven Brakman, Harry Garretsen and Charles van Marrewijk, Cross-Border Mergers and Acquisitions: On Revealed Comparative Advantage and Merger Waves, November 2005

1603 Erkki Koskela and Rune Stenbacka, Product Market Competition, Profit Sharing and Equilibrium Unemployment, November 2005

1604 Lutz Hendricks, How Important is Discount Rate Heterogeneity for Wealth Inequality?, November 2005

1605 Kathleen M. Day and Stanley L. Winer, Policy-induced Internal Migration: An Empirical Investigation of the Canadian Case, November 2005

1606 Paul De Grauwe and Cláudia Costa Storti, Is Monetary Policy in the Eurozone less Effective than in the US?, November 2005

1607 Per Engström and Bertil Holmlund, Worker Absenteeism in Search Equilibrium, November 2005

1608 Daniele Checchi and Cecilia García-Peñalosa, Labour Market Institutions and the Personal Distribution of Income in the OECD, November 2005

1609 Kai A. Konrad and Wolfgang Leininger, The Generalized Stackelberg Equilibrium of the All-Pay Auction with Complete Information, November 2005

1610 Monika Buetler and Federica Teppa, Should you Take a Lump-Sum or Annuitize? Results from Swiss Pension Funds, November 2005

1611 Alexander W. Cappelen, Astri D. Hole, Erik Ø. Sørensen and Bertil Tungodden, The Pluralism of Fairness Ideals: An Experimental Approach, December 2005

1612 Jack Mintz and Alfons J. Weichenrieder, Taxation and the Financial Structure of German Outbound FDI, December 2005

1613 Rosanne Altshuler and Harry Grubert, The Three Parties in the Race to the Bottom: Host Governments, Home Governments and Multinational Companies, December 2005

1614 Chi-Yung (Eric) Ng and John Whalley, Visas and Work Permits: Possible Global Negotiating Initiatives, December 2005

1615 Jon H. Fiva, New Evidence on Fiscal Decentralization and the Size of Government, December 2005

1616 Andzelika Lorentowicz, Dalia Marin and Alexander Raubold, Is Human Capital Losing from Outsourcing? Evidence for Austria and Poland, December 2005

1617 Aleksander Berentsen, Gabriele Camera and Christopher Waller, Money, Credit and Banking, December 2005 
1618 Egil Matsen, Tommy Sveen and Ragnar Torvik, Savers, Spenders and Fiscal Policy in a Small Open Economy, December 2005

1619 Laszlo Goerke and Markus Pannenberg, Severance Pay and the Shadow of the Law: Evidence for West Germany, December 2005

1620 Michael Hoel, Concerns for Equity and the Optimal Co-Payments for Publicly Provided Health Care, December 2005

1621 Edward Castronova, On the Research Value of Large Games: Natural Experiments in Norrath and Camelot, December 2005

1622 Annette Alstadsæter, Ann-Sofie Kolm and Birthe Larsen, Tax Effects, Search Unemployment, and the Choice of Educational Type, December 2005

1623 Vesa Kanniainen, Seppo Kari and Jouko Ylä-Liedenpohja, Nordic Dual Income Taxation of Entrepreneurs, December 2005

1624 Lars-Erik Borge and Linn Renée Naper, Efficiency Potential and Efficiency Variation in Norwegian Lower Secondary Schools, December 2005

1625 Sam Bucovetsky and Andreas Haufler, Tax Competition when Firms Choose their Organizational Form: Should Tax Loopholes for Multinationals be Closed?, December 2005

1626 Silke Uebelmesser, To go or not to go: Emigration from Germany, December 2005

1627 Geir Haakon Bjertnæs, Income Taxation, Tuition Subsidies, and Choice of Occupation: Implications for Production Efficiency, December 2005

1628 Justina A. V. Fischer, Do Institutions of Direct Democracy Tame the Leviathan? Swiss Evidence on the Structure of Expenditure for Public Education, December 2005

1629 Torberg Falch and Bjarne Strøm, Wage Bargaining and Political Strength in the Public Sector, December 2005

1630 Hartmut Egger, Peter Egger, Josef Falkinger and Volker Grossmann, International Capital Market Integration, Educational Choice and Economic Growth, December 2005

1631 Alexander Haupt, The Evolution of Public Spending on Higher Education in a Democracy, December 2005

1632 Alessandro Cigno, The Political Economy of Intergenerational Cooperation, December 2005

1633 Michiel Evers, Ruud A. de Mooij and Daniel J. van Vuuren, What Explains the Variation in Estimates of Labour Supply Elasticities?, December 2005

1634 Matthias Wrede, Health Values, Preference Inconsistency, and Insurance Demand, December 2005 